\title{
Role of Civil Society in Sustainable Urban Renewal (Machizukuri) after the Kobe Earthquake
}

\author{
Aleksandrina V. Mavrodieva ${ }^{1, * \mathbb{C}}$, Ratu Intan F. Daramita ${ }^{2}$, Arki Y. Arsono ${ }^{3}$, Luo Yawen ${ }^{1}$ and \\ Rajib Shaw ${ }^{1}$ \\ 1 Graduate School of Media and Governance, Keio University, Fujisawa 5322, Japan; \\ yawen16@sfc.keio.ac.jp (L.Y.); shaw@sfc.keio.ac.jp (R.S.) \\ 2 Ministry of Public Works and Housing, South Jakarta 12110, Indonesia; ratuintan01@gmail.com \\ 3 Agriculture, Foods, Marine and Fisheries Agency of Bantul, Bantul 55714, Indonesia; \\ arki.yudha.a@mail.ugm.ac.id \\ * Correspondence: almavrodieva@gmail.com; Tel.: +81-466-49-3404
}

Received: 16 November 2018; Accepted: 1 January 2019; Published: 10 January 2019

Abstract: 'Machizukuri' is translated by most commentators as 'place or city making' and mainly refers to the direct participation of citizens into urban planning and construction. The present paper discusses the concept and evolution of machizukuri from a social movement to 'soft-infrastructure' at city level, focused on serving community needs in post-disaster settings. The 1995 Great Hanshin-Awaji Earthquake in Kobe is chosen as the main case study, in order to review the role and process of machizukuri in disaster management in the context of urban renewal. This is followed by a discussion on the possibility of replicating this model in other contexts and the challenges which machizukuri and similar bottom-up groups are faced with in ensuring their sustainability. The paper argues that the culture and personal engagement of the citizens, and the commitment of national and local governments to cooperate with civil society groups, are essential in this process. Finally, the study suggests that the utilization of this concept has proved that there are undeniable benefits in engaging civil society in decision-making processes and initiatives, with the ultimate aim to create communities capable of overcoming the catastrophic consequences of disasters.

Keywords: machizukuri; civil society; grass-roots innovation; sustainable mechanisms; disaster response; urban development

\section{Introduction}

The concept of community-led planning is rooted in Japanese society since post World War II. After the war, the country felt it needed to regain its dignity. Its approach was to turn a devastated land into a country full-of-hope by rapid and intensive development. Industries in urban areas had led to increased pollution in most cities. These impacts prompted communities to form movements to engage and speak up about the increasing environmental and health issues they were facing. These community organizations developed under the name 'machizukuri'. Following these events, machizukuri has evolved as the most influential community-based organization in city planning, aiming to prevent unwanted changes and to promote compliance with citizens' needs in reconstruction and city development [1]. Later on, the influence of civil society groups also played a significant role in disaster management.

The present paper discusses the concept and evolution of machizukuri from social movement to 'soft-infrastructure' at a city level, focused on serving community needs in post-disaster settings. First, introduction or background of the establishment of machizukuri as community movement is presented to give a general idea of the process and its origins. After that, the 1995 Great Hanshin-Awaji 
Earthquake in Kobe was chosen as a case study, in order to review the role and process of machizukuri in disaster management in the context of urban renewal and land readjustment. Next, challenges in utilizing the machizukuri concept and practice in the process of city planning are discussed, as well as some lessons learned from community-based activities in participatory planning. Finally, the current research will seek to illustrate how these lessons could be replicated in new contexts in the region and beyond. Possible improvements or opportunities are proposed for establishing more sustainable mechanisms for civil society engagement in disaster management.

\section{Community-Based Post-Disaster Recovery}

Community-based disaster management has been in the focus of international organizations, non-for-profit organizations, and governments for more than two decades and practice has proved that there are numerous benefits of engaging residents in decision-making and planning. International frameworks-such as the Hyogo Framework for Action and the following Sendai Framework for Disaster Risk Reduction - encourage governments to work together with communities in devising new policies for disaster prevention and response, through raising awareness and building capacity [2].

The 2015 Global Assessment Report reiterated on the importance of community-based policies and practices. The report, however, also expressed the concern that even though the matter has become a mainstream topic in discussions at all levels of policy, the reality is that community empowerment and engagement is still rather marginal [3].

Matsuoka et al. [4] argue that the success of community-based approaches depends on two major factors: (1) the willingness of the people within a given community to be involved in disaster management; (2) and the links between the community and the authorities responsible for its governance. The authors are cautious about a relationship, where the community takes over the whole of the decision-making process and seizes to rely on the government administration. Instead, they prescribe a relationship, where community knowledge and capacities are recognized, enhanced, and included in the decision-making process and in disaster-related activities [4].

Linking to the first statement on people's level of participation, Aldrich [5] commented that social bonds are key in post-disaster recovery. The study suggested that whether local governments conducted activities adequately or not, it was the communities' that played the most important role at all stages of the disaster cycle [5]. The World Health Organization assessed that most lives are saved within the first few hours after a disaster, through local response teams. Therefore, the complex issues resulting from a disaster, related to restoring livelihoods and ensuring public health, are more efficiently addressed if the community is active and well organized [6].

One of the most difficult hurdles to overcome in community-based approaches for disaster management, however, is namely the issue of sustainability. Community involvement is often initiated by organizations and agencies for a specific project or only in the recovery phase of a disaster, after which the engagement is discontinued. Other issues might be related to the lack of funds or lack of well-established partnerships, community fatigue, or lack of ownership by the community [7].

Among the many case studies from research and practice there is but a stark example for long-term community engagement, not only in disaster management, but in various aspects of local development, which is the rather unique case of the Japanese practice of 'machizukuri'. Machizukuri has had an important transformative power both in mobilizing communities and in establishing new policies and processes for government-community collective decision-making. The authors consider that this concept could pave the way towards more sustainable policies and practice in civic engagement now and in the future.

\section{Development of the Machizukuri Concept}

'Machizukuri' is translated by most commentators as 'place or city making' and mainly refers to the direct participation of citizens into urban planning and construction. The desired outcome is neighborhoods which are built according to the needs and preferences of the local communities, 
reflecting the values and lifestyle of the people living in the area. This concept is a stark departure from the more traditional approach of top-down bureaucratic city planning. Machizukuri is based on the traditional strong connection of the Japanese people to their community and neighborhood and brings together citizens, small and large private businesses, experts, and volunteers, not only from the immediate locality, but also from other cities and regions [8].

The concept is not a new one. As mentioned earlier, the rapid industrial expansion in the interwar years and after World War II lead to increased urbanization, but also to increased pollution and to disruptions in the social fabric. A large movement was born as a result of the accumulated frustration of the people, demanding increased attention to the impacts of urbanization on health and the environment. In 1968, the government responded to this plight by passing the City Planning Law, which allowed local administrations to arrange their own local urban planning and development initiatives [9].

In the 1970s, the decentralization of decision-making power eased the process of accommodating the requirements of civil society and a number of local governments supported the establishment of machizukuri groups. In 1978, the establishment of a Machizukuri Council in Mano district in Kobe was seen as a means to an end in preventing population shrinkage through attracting young families to live in the area [8].

In the 1980s, the government established the Urban Design Department to facilitate citizens' involvement in urban planning and since the 1990s the concept has been widely used in a variety of activities, including architectural conservation projects. As a result of decades of experience, working together with civil groups and seeing the positive results from the cooperation, the Japanese changed the original term for 'urban planning' —in urban design [9].

In 1992, an amendment to the City Planning Law required that municipalities consult citizens in drafting a new Master Plan for urban development. Kobe completed its Master Plan in 1993, after extensive consultations with civil groups. These existing links, as well as the availability of a Master Plan itself, proved to be important factors during the response to and recovery from the Great Hanshin-Awaji Earthquake, which hit Kobe in 1995 [1]. In a sense, 1995 was a cornerstone year for the development and expansion of the machizukuri concept, and for the inclusion of civil society into disaster response and recovery in general.

\subsection{Case Study: Disaster Profile}

On 17 January 1995, a devastating earthquake with a seismic magnitude of 7.3 struck Japan's Hyogo Prefecture. The Great Hanshin-Awaji Earthquake occurred in Kobe City, built on a narrow 2 to $3 \mathrm{~km}$ wide coastal plain, surrounded by the Rokko Mountains and the Osaka Bay. The disaster took the lives of approximately 6000 people and injured over 30,000. It also demolished more than 200,000 buildings and damaged around 180,000 buildings, as fires took off after the immediate disaster. As a result, more than 300,000 people became homeless. The estimated economic loss amounted to approximately 200 billion USD [10].

Noda Hokubu and Matsumoto districts in West Kobe's Nagata Ward were identified as the most affected areas due to the fires. This was caused by the poor quality of house construction, as the many old timber wood houses lined on narrow streets in those neighborhoods fed the fires right after the earthquake. The neighborhood arrangement consequently hindered the fire-fighters' access the affected areas and many modern buildings with concrete columns also collapsed into the narrow streets [8].

The earthquake damaged several pivotal infrastructure networks. According to The Great Hanshin-Awaji Earthquake Statistics and Restoration Progress report, produced in 2012, the traffic networks were also disrupted, as the Hanshin Expressway Route 3 (Kobe Route) and Route 5 (Wangan Route) collapsed onto the road below. Railway and bullet train tracks were damaged as well. Healey [9] argued that this was the result of negligence in inner city development, whereas major development efforts were focused on the reclamation of land for the construction of artificial islands in the coastline 
area. However, the reclaimed lands were also affected by the combination of vertical and horizontal earthquake movement [10].

The levels of destruction and damage caused by the Kobe earthquake prompted a significant volunteer action and the activation of the local machizukuri groups. The active engagement of civil society in the response and recovery phases of the earthquake became a turning point in expanding the role and concept of machizukuri.

\subsection{Civil Society Engagement}

The rapid and large-scale land reconstruction in Kobe after the disaster exhibits the role of city administration in using decentralization as means to endorse 'build back better' in disaster management. One of the quick measures undertaken by the local government was to establish so called umbrellas for land reconstruction. Within a short period after the earthquake, the administration published policies for urban planning and tried to gain recognition for further decentralization as a long-term planning strategy. In addition, the local government published building restrictions policy for six areas on 1 February, followed by a law for Special Measures for the Reconstruction of Destroyed Areas, passed on 26 February. However, at first, the government did not consult or engage with the affected communities, opting for quick recovery and reconstruction. This resulted in opposition to the proposed projects, as the planned rebuilding location was far from the original neighborhood of the affected people. Citizens were also frustrated with the lack of information and clarity on the reconstruction work planned by the local authorities [11].

The communities, together with civil society organizations, quickly organized among themselves into machizukuri groups and put forward their demands. Most of the groups consisted of local land and property owners and residents with small businesses and were concentrated around urban redevelopment or readjustment areas [8,12]. The initial community response was started by some 30 volunteers from Kobe and the nearby cities. They organized themselves to effectively share information and bring together other machizukuri groups to coordinate planning activities. This network managed to provide essential assistance in matters such as legal issues and fundraising. They also organized a number of local festivals and community projects, which helped in overcoming the psychological trauma from the disaster, making citizens feel useful through making them a part of the process for the recovery of their own neighborhoods [12].

During the recovery phase it became apparent that there were several existing faults with pre-disaster urban planning and construction. Infrastructure was not built according to the claimed standards, revealing corrupt contracting practices and mismanagement. Another lesson was how important and efficient community response could be, as machizukuri groups were able to organize various representatives-including volunteers, urban planners, and academics-and to provide meaningful input to reconstruction initiatives. These groups also managed to connect to networks outside of Kobe, mobilizing additional support and funding. They also assisted in limiting the spread of the fires and in rescuing the elderly and injured people, providing basic supplies and shelter [9].

\subsection{Process and Innovation}

The concept of machizukuri became a great example of the participation of civil society in urban planning, and particularly in post-disaster urban redevelopment planning. The role of civil society groups encompassed the shared-values and lifestyles of citizens, delivered in a constructive manner, through regular meetings and consultations among community members and the local urban planners and specialist groups $[8,11]$.

The machizukuri organizations were, as a matter of fact, authorized in 1982 under the Kobe City Machizukuri Ordinance, long before the disaster occurred. Kobayashi [12] mentions that the residents could play an important role in the aftermath of the 1995 earthquake because they were accustomed to the city planning process, and because they received wide support among citizens. The 
local government recognized the voice of the community and engaged the machizukuri groups in the rebuilding process.

However, machizukuri engagement was not smooth in all areas. The initial absence of local machizukuri in land redevelopment in the Rokko-michi Station South Area, one of the worst affected areas, led the social movement to file a lawsuit against the City Planning Office. Relocated local residents at that time were shocked by the original plan from the administration, which was seen to detriment their social life and ties. As a result, a revised plan of the initial redevelopment plan, consisting of high-rise apartment buildings, was put forward. As a prerequisite it required the establishment of machizukuri council to accommodate community aspirations. This Council later became one of the bases for a legitimized participatory planning approach [8].

These processes provided the foundation for bridging local machizukuri groups with city officials in reconstruction planning. It aimed to improve livability by working with local administration in a more fluid manner within the technocratic top-down bureaucracy. The presence of supporting networks was also seen as one of the contributing factors for the local machizukuri process to deliver innovation and ideas through intense assistance. Partnerships with other groups and towns led to the creation of social activities. Planners, architects, academic researchers, and other specialists from outside of Kobe contributed to linking the machizukuri groups and the local government, effectively improving the communication between all stakeholders $[8,12]$. The specialists assisted in the creation of basic plans for the implementation of projects in land redevelopment, readjustment, and revitalization. Their proposals allowed for re-building the residential areas in a more cooperative way, with improved urban design, in order to provide more affordable housing to low-income residents, and to keep small parks around neighborhoods for social interaction $[8,9,11]$.

Efforts were also focused on maintaining the characteristics of the residential areas as they were prior to the disaster and on achieving the desired neighborhood. In Noda Hokubu district, the community agreed to the planned necessary street widening but insisted that streets remained narrow enough to allow social cohesion among neighbors [11]. Some additional urban features were installed in public spaces as requested by the residents, such as scattered small parks around the neighborhoods and a small meandering stream along the main road in Matsumoto district, with the purpose to increase livability, moving towards an eco-neighborhood. What is more, an integrated community center was built in the Rokko Park to ensure future re-developments were in accordance with the desires and the needs of the local citizens [8].

The contribution of machizukuri in Mano district was gradual and was focused on providing an environmentally-friendly and healthy neighborhood, aiming to attract newcomers, in an attempt to tackle the issue of population decline in the area. In comparison, the process in the Rokko-michi Station South Area was more radical, as citizens had more pressing demands [13]. This reflects the flexibility of the machizukuri concept and process in post-disaster reconstruction planning, as it allows for developing different approaches, depending on the characteristics of the residents, the specific needs, the neighborhood, and the leadership style itself.

\section{Machizukuri after Kobe}

Machizukuri groups have remained active since the Kobe earthquake and have provided significant support in later disasters and in general urban development across Japan and beyond. After the 1995 disaster authorities in Japan put efforts not only in enhancing communities' capacities to respond to crises, but also in linking local governments into networks and forming alliances between cities to encourage mutual help and assistance. When a typhoon struck the city of Toyoka in 2004, the alliance proved its effectiveness, as neighboring cities and prefectures rushed to assist the affected area. In 2011, the Union of Kansai Local Governments, consisting of seven prefectures, sent experts and personnel, emergency aid and goods, and assisted in building temporary shelters in the aftermath of the Great East Japan Earthquake [7]. 
In the response to the 2011 disaster, a top-down approach was still dominating, but here the role of local governments was sought, in order to understand and facilitate communities' involvement in the disaster relief efforts. One month after the disaster, the then Prime-Minister Naoto Kan established a Reconstruction Design Council with the aim to discuss the best approach to recovery. The outcome document, produced by the Council, clearly indicated that the community should be at the center of the recovery efforts [14].

The 2011 Tohoku earthquake highlighted the importance of engaging civil society in disaster response, pointing out the ability of machizukuri centers to efficiently collect funds, to organize group activities, to perform capacity building initiatives, and to support affected people with basic commodities and shelter. In some cases, the establishment of such groups was supported by the local municipalities. In other places, it was various experts and academic institutions, such as the University of Tokyo and the Iwate Prefecture University, who proposed the establishment of machizukuri. The process shows that the concept of machizukuri was highly valued and the role of the community was considered central, not only as impact receivers but also as recovery beneficiaries [15].

It is also worth pointing out that machizukuri groups have the potential to contribute at different levels or stages of disaster risk management. The Great East Japan Earthquake generated wide community participation and was valuable in disaster relief in terms of providing temporary housing facilities. In Otsuchi, it concentrated on housing planning, the layout of individual housing units, the location of housing, and the integration with other facilities for sustainable community rebuilding [15]. New innovative approaches were employed in the effort. Wooden decks were used to create alleys, which the community used for enhancing social interaction. The alleys connected with the support center, providing residents with access to care services. The wooden decks also connected citizens with shops and offices in the nearby Heita Park. The general activities of this community-based organization were continued after the Tohoku disaster and were since seen as "recovery machizukuri" [14].

Machizukuri activities became even more active in the post-reconstruction period. Since 2012, community-support funds have been increasing, providing assistance in 2013 for the development of the New Tohoku Leading Model Project. Some supporting networks of community activities were applied with regards to machizukuri funds and new collaboration mechanism for industrial development, by endorsing community business and health and wealth services. Later on, meetings and conferences were held, such as the conferences in October 2013 and February 2014, delivering an outcome report with proposals on industry and tourism, medical care and welfare, local community, disaster prevention, and education [14].

Another similar example is the so called 'Machizukuri Funds' initiative, which is in practice a charity fund supported by local residents, private sectors and the government, focusing on townscape preservation, community regeneration, tourism promotion, etc. By 2006, approximately 200 such funds were created, generating millions of Yen, entirely committed to 'social good' projects. Residents, who have donated to the Machizukuri Funds, often also become more interested and engaged with the various activities of the machizukuri groups [13].

Machizukuri groups have also been key in promoting climate change adaptation, which is relevant to disaster prevention efforts. In Kyoto, machizukuri groups have taken firm actions since 1997, when the city hosted the COP III conference. Civil society was an important part of establishing Kyoto's Global Warming Countermeasures Promotion Program, aiming to significantly reduce the city's carbon dioxide output. In 2010 the program was revised and the new agenda included monitoring of the policy progress on climate action, based on indicators, as well as specific measures such as (a) re-designing the city to be more walk- and bicycle-friendly; (b) encouraging local projects for private business innovation research; (c) creating Kyoto city carbon offset facility; (d) promoting better utilization of daylight hours, thus saving electricity. Furthermore, a 4.2-MW solar power plant was built to provide electric power to approximately 1000 households. All of these initiatives were possible because of the dedicated efforts of residents and civil society groups pushing for particular policies and monitoring their proper implementation [13]. 
Other countries have also taken interest in the Japanese experience in working together with civil society. Machizukuri has become particularly popular in Korea and Taiwan from 1980s onwards. In Korea is it called 'Maeul-Mandeulgi' and in Taiwan-'SheQu-YingZao'. The principle is considered an important part of community planning and townscape design and development. Countries such as New Zealand and the UK have also looked into how machizukuri practice can be transferred to the realities of their locality $[8,16]$.

The 'Maeul-Mandeulgi' practice in South Korea, for instance, started as a community initiative, without the participation of governmental bodies. Some cases date back from the early 1990s, when a group of families in Seongmisan Town, in Mapo-gu district, gathered around the idea to create a child cooperative. In the following decades, such spontaneous groups arose for different reasons, most notably after 2003 when a large group of residents combined efforts to protest against construction works on the nearby Seongmisan Mountain. These efforts had lasting effects in building the local community as such and in preserving the local area according to the needs and traditions of the dwellers. Community groups were also formed around various other initiatives, such as the preservation of historic city sites and the improvement of environmental preservation [17].

In the beginning, these groups saw very little support from fellow residents, civil society or the local governments but with time, and with the success of such activities, their prominence increased. In 2000, the local government of Seoul launched an official program as a response to the citizens' demands to restore and preserve a traditional residential area in the city. Later, in 2008, the Seoul Metropolitan Government launched a new community-based urban regeneration approach, which however, quickly lost popularity as it limited the availability of low-income rental housing, and it even resulted in large displacements and evictions of citizens, also cutting communal ties and culture. As a response, residents started to demolish walls and to repair some of the old houses and plant new gardens. A residents' committee has since then taken over the management of new facilities once the construction works were over. The committee has organized a number of local events and initiatives, such as festivals, urban gardening, care for children and the elderly and others, which significantly improved communal life [17].

In New Zealand, a self-organized group of citizens formed the Stoddart Point Regeneration Ideas Group (SPRIG) as a response to the 2010 Canterbury earthquakes, in the Diamond Harbour area. The networked was formed initially as an attempt to rebuild the keystone building of Godley House. The members of the group recognized their lack of skills and specific mandate to conduct works but felt they could still contribute to the official recovery procedures. To do so, they focused on collecting ideas from the local community, producing an 'ideas paper' at the end. The SPRIG organized community meetings, where people could raise their voices and through which awareness was raised [18].

The group, however, faced a number of difficulties. The members realized the risk of identifying themselves with the whole community and made sure to explain they did not take decision for the community as leaders, but worked with the community. Further on, even though legislation supporting stakeholders to develop community capacities to plan and take decision in post-disaster contexts existed (Civil Defence Emergency Management Act from 2002), in practice there were no mechanisms for civic engagement. Another issue was the argument for the lack of necessary skills and knowledge for reconstruction and engineering among the community members, as was the case with some communities during the Kobe earthquake. At the same time, the links between local government and citizens were not clear [18].

A plethora of other examples of community participation in post-disaster activities can be found, such as projects in Indonesia engaging citizens in house reconstruction after the disasters in 2004 (Aceh earthquake and tsunami), 2006 (Yogyakarta earthquake), and 2009 (West Sumatra earthquake) [19], or house reconstruction in New Zealand after the 2010 Canterbury earthquakes, in the Diamond Harbour area. Most of these examples, however, differ from the practice of machizukuri, as other movements are formed mainly ad hoc and disappear once the post-disaster work has been completed; as well as 
the fact that other groups have had a much narrower scope of action. As of today, South Korea seems to be the one country which has adopted most of what the machizukuri concept represents.

\section{Discussion}

Today, to a large extent, Kobe has recovered successfully from the devastating effects of the Great Hanshin-Awaji Earthquake and machizukuri groups have been active throughout the country to support relief and reconstructions efforts on various occasions ever since [9]. These efforts, however, have not always run smoothly. There are a number of challenges and conditions for establishing a more sustainable civil society engagement, based on the machizukuri principle, in Japan and outside of Japan.

\subsection{Institutional Constraints}

One of the criticisms, which occurred after the Kobe earthquake, was that the concept of machizukuri was undermined by the integration of civil society activities within the local government city planning strategy. Citizens viewed disaster recovery, environmental preservation, and economic welfare as issues to be addressed as a whole, while the administration separated these issues among different offices and agencies, thus making it more difficult to achieve an integrated approach [9]. To add to this, when discussing replicating this model in other countries or regions, it would mean that it would be governmental authorities who would initially create and implement such initiatives by trying to engage with local communities. Indeed, one of the issues which still remain as a topic for discussion is to what extent governmental bodies should coordinate, support, and regulate the process of community engagement.

At the same time, machizukuri groups do not always have enough legitimacy and power to have significant influence over local government's decision making. Experience is regarded as an important aspect of disaster risk reduction. Previous experience in the Mano community in Kobe, dealing with pollution issues, meant that the local machizukuri groups are prepared to deal with certain issues and were easily recognized as a capable partner by the citizens and the administration. Civil society groups with less experience find it more difficult to receive recognition regarding having a good perception of city planning [20]. This would mean that local administrations would need to engage with local representatives through open, transparent, and continuous consultations to seek their opinions, but also to develop needed capacities for self-reliance and sustainability, where such capacities are insufficient. As a social organization, the machizukuri group contains the advantages to acquire resources and to sustain their mobilization based on the voluntary contribution by residents representing a number of different professional areas [21]. However, it also means that some social disorganization is likely to be generated due to the lack of permanent community structures, which might hinder efficient collective action. New machizukuri groups might take time to form and coordinate during a disaster, as was the case with some of the groups during the Kobe earthquake, which took a very long time to come together and develop coordinated demands and initiatives [22].

\subsection{Aging Issue}

Moreover, the declining population of Kobe and other areas in Japan represents one of the most challenging problems for the country. The decreasing numbers of work force may also become one of the key challenges for the development of sustainable mechanisms for civil society driven innovation in Japan and in other countries with aging populations. The shrinking numbers of young families would mean that it will be more difficult to maintain the existence of machizukuri and other bottom-up community groups, as those will require energy and commitment [23].

\subsection{Lack of Budget}

The limited government and public sector investment in supporting running machizukuri groups could hinder the capacity and sustainability of such structures over time. Furthermore, local economic 
decline and poverty can be another challenge for urban renewal activities. Machizukuri groups rely mainly on the local culture and readiness of its residents. The limited financial capabilities of individual households would lead to less engagement in civil society activities and to the potential loss of civil action capacity and memory [13].

Community funds could be established where citizens donate a negligible amount of money at certain intervals, and which would accumulate over time, similar to the already mentioned 'Machizukuri Funds'. These funds represent charitable trusts, where citizens, local governments and private business and the central government all make contributions, promoting the idea as a fund to be used for townscape preservation and tourism development. By 2005, an amount of 188 million Yen was contributed to the Machizukuri funds, of which 14 million Yen came from private individuals, and 20 million yen from businesses and corporations [13]. Encouraging citizens to donate sums to such funds would require engagement and discussions with the local communities, awareness raising, as well as some capacity building. Most of all, it would require providing the space for residents to create links with the representatives of the same community and acquire a sense of responsibility towards their environment.

\subsection{Community Fatigue}

Machizukuri, as well as the 'Maeul-Mandeulgi' movement in South Korea, at first emerged as a reaction to policies that did not correspond with what citizens viewed as their needs, and were later transformed into more permanent civic engagement with bodies and representatives. If civil groups evolve around a single problem or as a form of protest against certain policies, their evolution into an established form of civic engagement would require constant commitment from the community members.

In other words, to successfully achieve the development of machizukuri, or a similar model of community engagement, the local residents' continuous motivation and interest in the urban renewal processes should be achieved as well. [24]. The meaningful involvement of residents in city/town upgrading and rebuilding activities should be encouraged by the local government and machizukuri or other civil society councils or structures [25].

Hein [11] mentions that further decentralization of planning prerogatives, a new perspective on the role of the architects and an increased use of consultants could help overcome some of the obstacles in urban reconstruction and design. Further on, for the establishment of more sustainable machizukuri groups, several measures could be taken into account. These include the setting up of predefined budgets and funds for civil society engagement, and reaching out to other non-traditional actors, such as private sector representatives and academia, in order to secure wider support and more funding opportunities. Inclusion of residents from different backgrounds, ages, and genders, as well as representatives of immigrant groups, will ensure wide social inclusion and better understanding of the real needs of the communities 02 [11].

Towards the end of the 1980s and the beginning of the 1990's, for instance, the machizukuri groups started cooperating more and more with private businesses, mainly at the local level. Such collaborations resulted in the creation of new parks and public spaces and in agreements for the preservation of historic houses and sites with cultural significance [26]. Community-based approaches in places outside of Japan could look into this positive practice for collaborating with local private sectors for small-scale projects, thus also deepening the links between different representatives of the community, who can bring various skills and professional knowledge.

One of the venues for engagement and information sharing on possibilities and ways to contribute to machizukuri or similar groups could be during the post-disaster or regular social activities, such as festivals, and gardening or other initiatives, where knowledge on disaster prevention, first aid and neighborhood development could be easily transmitted and discussed with participating citizens [8]. 


\subsection{Specificities of the Japanese Society and Culture}

It is important to mention that the machizukuri experience is based on a number of prerequisites and replicating it outside of Japan might face certain difficulties. It is necessary to discuss some of the specificities of the Japanese culture and society, in order to assess the possible application of the principle elsewhere.

Japanese society is characterized by stable local populations and relatively homogenous population. Links between generations, neighbors, and communities are strong both vertically and horizontally, creating strong social bonds and shared values. A strong sense of social obligation and support for the common social good are also essential for ensuring continuous engagement and trust between citizens, businesses and local institutions. The willingness of municipalities to listen to the voices and work together with residents as equal partners is of major importance to the existence of active civil society groups [27].

This means that applying the machizukuri concept outside of Japan would require stable and reliable administration and institutions, which have built trust with local civil society. Predefined funds, strong social commitment to volunteering, and communities' invested interest in improving the living conditions of their own neighborhoods are also crucial in this process. For the last condition to take place, especially in regards to post-disaster recovery activities, some knowledge sharing and capacity building would be beneficial in order to engage wider civil support.

Based on the Kobe experience, Shaw and Goda [28] summed up a list of recommended actions to follow, in order to ensure more sustainable participation of communities. These include: (1) dedicated inclusion of communities into discussions and decision-making processes; (2) taking into account and utilizing the values and traditions of communities; (3) exploring business opportunities within the community to ensure economic security and available funds for recovery; (4) Encouraging local leaders to take action [28]. To this, a few more recommendations could be added, namely: inclusion of disaster-related lessons or training into education; replication of community's success to set an example and build long-term local initiatives; and wide inclusion of community members to ensure representation of all affected groups [6].

Finally, it should not be forgotten that such processes always take time and continuous efforts, and need re-adjusting after tests and trials. The Japanese concept of machizukuri has been evolving for decades and has been transformed to serve a number of purposes. Other nations can make use of its flexibility and adaptability and transform it in a way that would serve their particular local requirements [9].

\section{Conclusions}

The 1995 Great Hanshin-Awaji Earthquake and the 2011 Great East Japan Earthquake left Japan in the rubble of destruction and had profound effects on the lives of thousands of people. However, the strong voluntary commitment of ordinary residents and the pre-existing social formations in the face of local machizukuri groups significantly facilitated the recovery of the affected areas in a manner that would correspond to the actual needs of the communities. Civil society showed resilience and ability to coordinate and cooperate with a number of actors, creating a new model for disaster resilience and reconstruction.

In order to ensure sustainability of this model, certain measures and policies need to be at place. The culture and personal readiness for support from citizens, and the commitment of national and local governments to cooperate with civil society groups, are essential in establishing a long-term model for engagement. Pledged funding, trust among actors, and timely information sharing are detrimental for the success of grass-root participation.

Even if the machizukuri concept per se would not be applicable in its entirety to countries and areas outside of Japan, it could be adjusted to fit other local specificities and contexts, putting the needs of communities at the forefront of reconstruction and development efforts. Most of all, this experience shows the undeniable benefits of engaging residents and civil society in decision-making processes 
and initiatives, with the ultimate aim to create communities capable of overcoming the catastrophic consequences of disasters and other harmful events. It also shows the importance of community links and the sense of responsibility towards our own neighborhood and our own community, which could be essential in saving lives during disasters and in post-disaster recovery.

Author Contributions: A.V.M. was responsible for the overall coordination among the authors, for the body and flow of the paper, and for all editing. She has provided the majority of the input in chapters 2, 4, 5 and 6 , and some input in chapters 1 and 3. R.I.F.D. has provided the main input in chapters 1 and 3 and some input in chapter 4 . L.Y. and A.Y.A. have provided some input in chapter 5. R.S. has provided overall coordination and guidance for the structure, flow and focus of the paper.

Funding: This research received no external funding.

Acknowledgments: The first author is thankful to the Ministry of Education, Culture, Sports, Science, and Technology (MEXT) of Japan for the provided scholarship to conduct research in the field of disaster risk reduction. The second and fourth authors are thankful to the Pusbindiklatren Bappenas Programme, Government of Indonesia, for the provided scholarship. The authors also acknowledge the support received from the Disaster Resilience and Sustainable Development Program of the Graduate School of Media and Governance, Keio University, Japan, in conducting this study.

Conflicts of Interest: The authors declare no conflict of interest.

\section{References}

1. Sorensen, A.; Koizumi, H.; Miyamoto, A. Machizukuri, Civil Society, and Community Space in Japan. In The Politics of Civic Space in Asia: Building Urban Communitie; Routledge: New York, NY, USA, 2009; pp. 33-50.

2. Shaw, R. (Ed.) Community Practices for Disaster Risk Reduction in Japan; Springer: Kyoto University, Kyoto, Japan, 2014. [CrossRef]

3. UNISDR. Global Assessment Report (GAR) on Disaster Risk Reduction. Available online: https://www. preventionweb.net/english/hyogo/gar/2015/en/gar-pdf/GAR2015_EN.pdf (accessed on 22 December 2018).

4. Matsuoka, Y.; Joerin, J.; Shaw, R.; Takeuchi, Y. Partnership between City Government and Community-Based Disaster Prevention Organizations in Kobe, Japan in Community Based Disaster Risk Reduction; Emerald: Bingley, UK, 2012; pp. 151-184.

5. Aldrich, D. Building Resilience: Social Capital in Post-Disaster Recovery; The University of Chicago Press: Chicago, IL, USA, 2012.

6. Kafle, S.K.; Murshed, Z. Community-Based Disaster Risk Management for Local Authorities; Participant's Workbook; Asian Disaster Preparedness Center (ADPC); Available online: https://www.unisdr.org/files/ 3366_3366CBDRMShesh.pdf (accessed on 22 December 2018).

7. Shaw, R. Post Disaster Recovery: Issues and Challenges. In Disaster Recovery. Used or Misused Development Opportunity; Shaw, R., Ed.; Springer: Kyoto University, Kyoto, Japan, 2014; pp. 1-13. [CrossRef]

8. Mamula-Seadon, L.; Kobayashi, I.; Maki, N. Place-Making after a Disaster: Japanese Practice of Machizukuri. Available online: https://goo.gl/YCktg2 (accessed on 19 August 2018).

9. Healey, P. Developing Neighborhood Management Capacity in Kobe, Japan: Interactions between Civil Society and Formal Planning Institutions. Available online: https://goo.gl/rsMvGX (accessed on 5 August 2018).

10. Chung, R. The January 17, 1995 Hyogoken-Nanbu (Kobe) Earthquake. Available online: https://www.govinfo.gov/content/pkg/GOVPUB-C13-41457216365bcb5b9a5dc4db97b98f76/pdf/GOVPUBC13-41457216365bcb5b9a5dc4db97b98f76.pdf (accessed on 27 July 2018).

11. Hein, C. Toshikeikaku and Machizukuri in Japanese Urban Planning: The Reconstruction of Inner City Neighborhoods in Kōbe. Japanstudien 2002, 13, 221-252. [CrossRef]

12. Kobayashi, I. Machizukuri (Community Development) for Recovery Whose Leading Role Citizens Play. J. Disaster Res. 2007, 2, 359-371. [CrossRef]

13. Kusakabe, E. Advancing sustainable development at the local level: The case of Machizukuri in Japanese cities. Prog. Plan. 2013, 80, 1-65. [CrossRef] 
14. Murakami, K.; Wood, D.M.; Tomita, H.; Miyake, S.; Shiraki, R.; Itonaga, K.; Dimmer, C. Planning Innovation and Post-Disaster Reconstruction: The Case of Tohoku, Japan/Reconstruction of Tsunami-Devastated Fishing Villages in the Tohoku Region of Japan and the Challenges for Planning/Post-Disaster Reconstruction in Iwate and New Planning Challenges for Japan/Towards a 'Network Community' for the Displaced Town of Namie, Fukushima Resilience Design and Community Support in Iitate Village in the Aftermath of the Fukushima Daiichi Nuclear Disaster/Evolving Place Governance Innovations and Pluralising Reconstruction Practices in Post-Disaster Japan. Plan. Theory Pract. 2014, 15, 237-242. [CrossRef]

15. Koizumi, H.; Tsuji, M. Community Design in the Recovery Following the March 2011 Earthquake and Tsunami. In The 2011 Japan Earthquake and Tsunami: Reconstruction and Restoration; Santiago-Fandiño, V., Sato, S., Maki, N., Iuchi, K., Eds.; Advances in Natural and Technological Hazards Research; Springer: Cham, Switzerland, 2017; Volume 47. [CrossRef]

16. Parker, G.; Woodend, L. East-Side Story: Japanese Machizukuri, Neighbourhood Planning, And Localism in England. Town \& Country Planning. Available online: http://www.jlgc.org.uk/en/pdfs/GP_LW.pdf (accessed on 18 August 2018).

17. Sik, I.C.; Kriznik, B. Community-Based Urban Development. Evolving Urban Paradigms in Singapore and Seoul. In Advances in 21st Century Human Settlements; Springer Nature Singapore Pte Ltd.: Singapore, 2017. [CrossRef]

18. Love, R.; Vallance, S. The role of communities in post-disaster recovery planning: A Diamond Harbour case study. Lincoln Plan. Rev. 2013, 5, 3-9.

19. Ophiyandri, T.; Amaratunga, D.; Pathirage, C. Advantages and Limitations of Community-based Post-disaster Housing Reconstruction Projects. Available online: https://goo.gl/Gk3GJ6 (accessed on 15 December 2018).

20. Evans, N. Machi-Zukuri as a New Paradigm in Japanese Urban Planning: Reality or Myth? Jpn. Forum 2002, 14, 443-464. [CrossRef]

21. Sorensen, A.; Funck, C. (Eds.) Living Cities in Japan: Citizens' Movements, Machizukuri and Local Environments; Routledge: New York, NY, USA, 2007.

22. Bosman, C. Building Community Places-Machizukuri-Neoliberalism, Suburbanization and 'Americanization'. Int. Plan. Stud. 2007, 12, 309-325. [CrossRef]

23. Sorensen, A. Liveable cities in Japan: Population ageing and decline as vectors of change. Int. Plan. Stud. 2006, 11, 225-242. [CrossRef]

24. Hashimoto, S.; Sato, Y. Participatory rural planning in japan: Promises and limits of neighborhood associations. Paddy Water Environ. 2008, 6, 199-210. [CrossRef]

25. Okada, N.; Fang, L.; Kilgour, D.M. Community-based decision making in Japan. Group Decis. Negot. 2013, 22, 45-52. [CrossRef]

26. Nishimura, Y. From City Planning to Machizukuri. A Japanese Experience of Community Planning. Available online: https://goo.gl/Ni6YWn (accessed on 2 August 2018).

27. Issarathumnoon, $\mathrm{W}$. The Machizukuri Bottom-Up Approach to Concervation of Historic Communities: Lessons for Thailand. Available online: http://utud.sakura.ne.jp/research/publications/_docs/2005aij/ wi041112.pdf (accessed on 26 August 2018).

28. Shaw, R.; Goda, K. From disaster to sustainable civil society: the Kobe experience. Disasters 2004, $28,16-40$. [CrossRef] [PubMed]

(C) 2019 by the authors. Licensee MDPI, Basel, Switzerland. This article is an open access article distributed under the terms and conditions of the Creative Commons Attribution (CC BY) license (http://creativecommons.org/licenses/by/4.0/). 